\title{
How much personal care in four group practices?
}

\author{
George K Freeman, Sally C Richards
}

\author{
Abstract \\ Objective-To establish the degree of continuity \\ of care in general practice.
}

Design-Retrospective study of the records of all eligible patients attending the surgery at randomly selected sessions.

Setting-Four large group practices in the Southampton Health District, one of which operated a strict system of personal lists.

Patients - 776 Patients who had been registered for at least two years and had consulted at least 12 times over six years or less.

Main outcome measures-Continuity score for each patient calculated from the number of consultations (out of the past 12) with his or her usual doctor. Number of the times the patients had consulted the doctor with whom they were registered.

Results - In the practice with personal lists a mean of 10 of the 12 consultations had been with the same doctor ( $83 \%$ of consultations), but in the three practices with combined lists the means were $\mathbf{5 . 9}$ $(49 \%), 6.2(52 \%)$, and $6.9(58 \%)$. Continuity was associated with increased age and with the recording of a major problem. In the practices with combined lists 63 of 72 children consulted at least five different doctors. Only 140 of 489 patients currently in the practice who were identified as being registered with a doctor had most usually consulted that doctor in the practices with combined lists.

Conclusions - Personal continuity of care may be fairly low in group practice, especially for younger and healthier patients registered at practices with combined lists. These findings support the Department of Health's recent decision to make "target payments" (for cervical smears and childhood immunisations) to groups rather than to individual principals but pose a question for the future of individual clinical responsibility.

\section{Introduction}

Most British patients are now registered with a group practice. Often the patients can consult any doctor in the group. ' Nevertheless, lip service continues to be paid to continuity of care in the sense that patients should normally consult the same doctor on each visit. ${ }^{2}$ How much is this happening, and which patients are most likely to consult the same doctor? The new general practitioners' contract has removed the group practice allowance and puts increased emphasis on a general practitioner's availability and accountability for his or her list of patients. Indeed, initially the new target payments for immunisations and cervical smears were to be linked to the lists of individual doctors rather than to those of the group as a whole. How likely are patients to consult the doctor with whom they are registered? What are the chances of patients consulting the same doctor at most consultations? Pereira Gray looked at these questions in his practice of three partners in 1979. ${ }^{3}$

Previous studies in Wessex region have examined the priority given by general practitioners to personal continuity of care ${ }^{4}$ and the actual working of appointments systems in group practices. ${ }^{5}$ Before studying patients' attitudes to continuity and clinical outcomes we looked at medical records to establish the level of continuity actually encountered by a large sample of patients. We studied four group practices with different ways of organising their lists, firstly, to identify from patients' records the doctor with whom they were registered and the doctor(s) actually consulted at the most recent 12 consultations; secondly, to look for differences between the practices in terms of the number of different doctors consulted and how much patients consulted their registered doctor; and, thirdly, to find the relation between continuity of care and the age, sex, consultation rate, and length of registration of patients and whether they had one or more major problems recorded.

\section{Patients and methods}

\section{THE PRACTICES}

We studied four suburban group practices in the Southampton district. They were chosen because the principals had expressed interest in the results of a previous survey on continuity of care and because they were large enough for the question of priority of personal continuity to be an issue. ${ }^{3}$ Each had a list of about 13000 patients cared for by six or seven principals. Three practices $(\mathrm{A}, \mathrm{B}$, and $\mathrm{C})$ each ran a combined list system, had trainees, and had a branch surgery. In these practices the patients could consult any doctor and were sometimes encouraged to do so if their problem was urgent.

The fourth practice (D) had a strict system of personal lists and practised from one site without trainees at the time of the study. The patients were strongly encouraged to consult only the doctor with whom they were registered. The administrative features of the practices were given in a report of a study of their receptionists and appointment systems. ${ }^{5}$

\section{SELECTION OF RECORDS}

All records of patients consulting at randomly selected sessions (excluding any special clinics) were examined for eligibility up to a maximum of 200 per practice. Patients included in the study had had at least 12 recorded consultations, including home visits, with a doctor over six years or less and had been registered for at least two years. Consultations solely for antenatal care were excluded because we thought that they represented enforced continuity.

\section{COLLECTION AND ANALYSIS OF DATA}

The following items were noted from each patient's record: date of birth, date of registration, sex, doctor of registration, and doctor(s) consulted and major problems recorded at past 12 consultations (with dates). The doctors were identified by their handwriting with the help of receptionists. A major problem was defined as one in a list agreed in GKF's practice for 
recording in a computerised register of diseases (list available from GKF).

A continuity score was obtained for each patient, this being the number of consultations (out of the past 12) with his or her usual doctor. Expressed as a percentage, this is the usual provider continuity index. ${ }^{6}$ The time from the first to the twelfth (most recent) consultation defined the consultation rate. The records were examined by SCR and a $10 \%$ random sample checked by GKF.

A tenth of consultations in practice A were recorded only by date stamps. As observation in this practice confirmed that these normally represented consultations with more than one doctor we included them and listed the information as blank. Any number of blank consultations was counted as one extra doctor per patient.

In practices $A$ and $B$ a proportion of patient's records indicated that they were registered with a doctor who had since retired or gave no indication at all of registration.

TABLE I-Consultations with principals and trainees or locums in each of four practices with combined or personal lists. Figures are numbers (percentages) of 12 recorded consultations for each patient

\begin{tabular}{|c|c|c|c|c|}
\hline \multirow[t]{2}{*}{. } & \multicolumn{3}{|c|}{ Practices with combined lists } & \multirow{2}{*}{$\begin{array}{c}\text { Practice with } \\
\text { personal lists } \\
D \\
(n=200)\end{array}$} \\
\hline & $\underset{(n=177)}{A}$ & $\underset{(n=199)}{B}$ & $\begin{array}{c}C \\
(n=200)\end{array}$ & \\
\hline $\begin{array}{l}\text { Consultations with: } \\
\text { Principals } \\
\text { Trainees or locums } \\
\text { Unknown (blank entries) }\end{array}$ & $\begin{array}{r}1661(78) \\
258(12) \\
205(10)\end{array}$ & $\begin{array}{c}1780(75) \\
604(25) \\
4\end{array}$ & $\begin{array}{r}1979(82) \\
421(18)\end{array}$ & $\begin{array}{c}2343(98) \\
49(2) \\
8\end{array}$ \\
\hline Total & $2124(100)$ & $2388(100)$ & $2400(100)$ & $2400(100)$ \\
\hline
\end{tabular}

TABLE II-Mean continuity scores of patients attending four practices with combined (practices $A-C$ ) or personal (practice D) lists. Figures are mean numbers (percentages) of past 12 consultations that were with usual doctor

Practice Mean score

\begin{tabular}{lr}
\hline$A(n=177)$ & $6 \cdot 2(52)$ \\
$B(n=199)$ & $5 \cdot 9(49)$ \\
$C(n=200)$ & $6.9(58)$ \\
$A+B+C(n=576)$ & $6 \cdot 3(53)$ \\
$D(n=200)$ & $10 \cdot 0(83)$
\end{tabular}

\section{Results}

PATIENTS' AGE GROUPS AND MAJOR PROBLEMS

We examined the records of 776 patients satisfying the entry criteria: 177 from practice A, 199 from practice B, and 200 each from practices C and D. Age distribution was similar among the practices except that there was a higher proportion of patients aged $\geqslant 65$ and a lower proportion aged 15-44 in practice A. Overall, there were 92 children aged 0-14 years, 298 patients aged 15-44, 212 middle aged adults aged 4564 , and 174 elderly patients aged $\geqslant 65$.

Over half of the patients (405) had one or more major problems recorded except in practice A $(69,39 \%)$,

TABLE III-Continuity scores in patients attending each of four practices with combined or personal lists. Figures are numbers (percentages) of patients

\begin{tabular}{|c|c|c|c|c|c|}
\hline \multirow[b]{2}{*}{ Continuity score } & \multicolumn{4}{|c|}{ Practices with combined lists } & \multirow{2}{*}{$\begin{array}{c}\text { Practice with } \\
\text { personal lists } \\
\text { D } \\
(\mathrm{n}=200)\end{array}$} \\
\hline & $\underset{(n=177)}{A}$ & $\begin{array}{c}\mathrm{B} \\
(\mathrm{n}=199)\end{array}$ & $\begin{array}{c}C \\
(n=200)\end{array}$ & $\begin{array}{l}A+B+C \\
(n=576)\end{array}$ & \\
\hline $\begin{array}{l}2- \\
4- \\
7- \\
10-12\end{array}$ & $\begin{array}{l}25(14) \\
76(43) \\
48(27) \\
28(16)\end{array}$ & $\begin{array}{l}48(24) \\
71(36) \\
60(30) \\
20(10)\end{array}$ & $\begin{array}{l}20(10) \\
78(39) \\
59(30) \\
43(22)\end{array}$ & $\begin{array}{r}93(16) \\
225(39) \\
167(29) \\
91(16)\end{array}$ & $\begin{array}{c}8(4) \\
68(34) \\
124(62)\end{array}$ \\
\hline
\end{tabular}

TABLE IV - Number (percentage) of patients attending four practices with combined (practices $A-C$ ) or personal (practice D) lists whose usual doctor was their registered doctor

\begin{tabular}{lr}
\hline Practice & $\begin{array}{c}\text { Usual doctor } \\
\text { same as } \\
\text { registered } \\
\text { doctor }\end{array}$ \\
\hline$A(n=103)$ & $31(30)$ \\
$B(n=187)$ & $49(26)$ \\
$C(n=199)$ & $60(30)$ \\
$A+B+C(n=489)$ & $140(29)$ \\
$D(n=197)$ & $190(96)$ \\
\hline
\end{tabular}

Often no current registered doctor was recorded, especially in practice where summary sheets had not been completed at the time of the study.

\section{CONSULTATIONS WITH PRINCIPALS AND TRAINEES}

Table I shows the total number of consultations recorded in each practice with principals or assistants (normally trainees). Practices A, B, and C each had two trainees at the time of the study. Practice $B$ used locums, some of whom were former trainees, more than the other practices.

\section{DELIVERY OF CARE BY THE SAME DOCTOR}

Continuity of doctor differed greatly between the practices with combined and personal lists. In the practices with combined lists (A-C) 258 of the 576 patients $(45 \%)$ had consulted the same doctor for more than half of their 12 consultations (continuity score of $\geqslant 7$ ) and continuity scores ranged from 2-12. In the practice with a personal list (D) patients had had a minimum of five consultations with one doctor and a fifth of the 200 patients (43) had a continuity score of 12 , and 192 patients had consulted the same doctor for more than half of their consultations (tables II and III).

In practice $\mathrm{D}$ the usual doctor consulted was the doctor with whom the patients were registered in 190 cases $(96 \%)$. In practices $\mathrm{A}-\mathrm{C}$ this was much less common, with a mean of $29 \%$ of patients usually consulting the doctor with whom they were registered (table IV). Only 103 (58\%) of the patients in practice A, however, had a registered doctor who was identifiable and currently in the practice.

\section{FACTORS ASSOCIATED WITH PERSONAL CONTINUITY}

The most crucial factor associated with continuity was the practice-specifically practice $\mathrm{D}$, where the odds of having consulted the same doctor for more than half of the past 12 consultations were over 60 times those in practices $\mathrm{A}$ and $\mathrm{B}$; for practice $\mathrm{C}$ the odds ratio was much smaller but still significant. The patients' age groups showed a significant and steep gradient of odds ratios, the elderly being more than 16 times as likely to achieve good continuity as children.

Other significant factors included the recording of a major problem and a higher consulting rate (that is, 12 consultations in a shorter time). Overall, there was no association with the sex of the patient or with the length of time patients had been registered in the practice (table V).

\section{EXPERIENCE OF DIFFERENT DOCTORS}

More than half of the patients in practices A-C had consulted at least five different doctors over their last 12 consultations. In practice B more than a quarter of the patients had consulted seven or more different doctors, the maximum being 10 (table VI). Many of these doctors were trainees, who contributed up to a quarter of all consultations recorded (table I). Only 59 patients $(10 \%)$ in these practices had consulted five or more principals. Six patients had consulted all the principals in their practice over 12 consultations.

The number of different doctors consulted was also (inversely) correlated with age. In practices A-C 63 (88\%) of 72 children aged $0-14$ had consulted five or more doctors compared with only $28(22 \%)$ of 130 patients aged $\geqslant 65$. By contrast, in practice $D$ only three of the 20 children and two adults had consulted five or more different doctors.

\section{Discussion}

The study shows that patients may consult many different doctors in a group practice - up to 10 in 12 consultations. This finding applies particularly to children, for whom appointments are likely to be requested at short notice. In addition, less than $30 \%$ of patients in practices A-C usually consulted the doctors with whom they were registered. The results were completely different in the practice that specifically encouraged patients to consult their own doctor.

Several patients in practices A-C had high levels of continuity and a few even consulted the same doctor for all 12 consultations. Typically these patients were older and had a definite and perhaps chronic problem such as hypertension, for which follow up was predictable and appointments with the chosen doctor could be arranged well in advance. Otherwise movement between doctors often seemed haphazard, and if a patient consulted a different doctor at the start of an illness he or she might see this doctor for several consultations. A lower consulting rate was associated 
TABLE V-Association of six variables with higher continuity score ( $\geqslant 7-12)$ in patients attending each of four practices with combined or personal lists

\begin{tabular}{|c|c|c|c|c|c|c|}
\hline \multirow[b]{2}{*}{ Variables } & \multirow{2}{*}{\multicolumn{4}{|c|}{ Odds ratio ( $95 \%$ confidence interval) }} & \multicolumn{2}{|c|}{ No of patients } \\
\hline & & & & & $\begin{array}{l}\text { With continuity } \\
\text { score } \geqslant 7-12\end{array}$ & Total \\
\hline \multicolumn{7}{|l|}{ Practice: } \\
\hline \multicolumn{6}{|l|}{ Combined list: } & 177. \\
\hline B & \multirow{2}{*}{\multicolumn{4}{|c|}{$\begin{array}{l}1.0(0.6 \text { to } 1.6) \\
1.9(1.2 \text { to } 3.0)\end{array}$}} & 80 & 199 \\
\hline $\mathrm{C}$ & & & & & 102 & 200 \\
\hline Personal list (D) & \multicolumn{4}{|c|}{$62.9(27.0$ to $146 \cdot 6)$} & 192 & 200 \\
\hline \multicolumn{7}{|l|}{ Age: } \\
\hline $0-$ & \multirow{5}{*}{\multicolumn{3}{|c|}{$\begin{array}{l}1 \cdot 0 \\
3 \cdot 1(1 \cdot 5 \text { to } 6 \cdot 4) \\
10 \cdot 2(4 \cdot 6 \text { to } 22 \cdot 5) \\
16 \cdot 7(7 \cdot 3 \text { to } 38 \cdot 5)\end{array}$}} & & 26 & 92 \\
\hline 15 & & & & & 141 & 298 \\
\hline 45- & & & & & 146 & 212 \\
\hline$\geqslant 65$ & & & & & 137 & 174 \\
\hline \multicolumn{4}{|c|}{ Major health problem recorded: } & & & \\
\hline No & \multirow{2}{*}{\multicolumn{3}{|c|}{$\begin{array}{l}1 \cdot 0 \\
1 \cdot 6(1 \cdot 1 \text { to } 2 \cdot 3)\end{array}$}} & & 171 & 371 \\
\hline Yes & & & & & 279 & 405 \\
\hline \multicolumn{7}{|l|}{ No of consultations/year: } \\
\hline$<3$ & \multicolumn{3}{|c|}{1.0} & & 57 & 115 \\
\hline $3-$ & \multirow{2}{*}{\multicolumn{3}{|c|}{$\begin{array}{l}1.0(0.5 \text { to } 1.8) \\
1.8(1.0 \text { to } 3.1)\end{array}$}} & & 109 & 219 \\
\hline $6-$ & & & & & 166 & 275 \\
\hline$\geqslant 12$ & \multicolumn{3}{|c|}{$2 \cdot 3(1 \cdot 2$ to $4 \cdot 4)$} & & 118 & 167 \\
\hline Years registered with $\mathrm{pr}$ & & & \\
\hline $2-$ & \multirow{2}{*}{\multicolumn{3}{|c|}{$\begin{array}{l}1.0 \\
0.9(0.5 \text { to } 1.5)\end{array}$}} & & 111 & 214 \\
\hline 7. & & & & & 94 & 168 \\
\hline $13-$ & \multirow{2}{*}{\multicolumn{3}{|c|}{$\begin{array}{l}0.7(0.4 \text { to } 1.2) \\
1.0(0.6 \text { to } 1.8)\end{array}$}} & & 107 & 202 \\
\hline$\geqslant 25$ & & & & & 130 & 178 \\
\hline Sex: & \multirow{2}{*}{\multicolumn{3}{|c|}{ 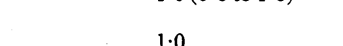 }} & & & \\
\hline M & & & & & 180 & 306 \\
\hline $\mathrm{F}$ & \multicolumn{3}{|c|}{$1.0(0.7$ to 1.4$)$} & & 270 & 470 \\
\hline \multicolumn{7}{|c|}{$\begin{array}{l}\text { Odds ratios were calculated to allow for the effects of the five other factors. For each factor odds ratios are expressed } \\
\text { relative to a baseline comparison group. When the } 95 \% \text { confidence intervals do not overlap the odds ratios are } \\
\text { significantly different at the } 5 \% \text { level. }\end{array}$} \\
\hline \multicolumn{7}{|c|}{$\begin{array}{l}\text { TABLE VI }-N \text { umber of doctors consulted during past } 12 \text { consultations by patients attending each of four } \\
\text { practices with combined or personal lists. Figures are numbers (percentages) of patients }\end{array}$} \\
\hline \multirow[b]{2}{*}{ No of different doctors } & \multicolumn{4}{|c|}{ Practices with combined lists } & \multirow{2}{*}{\multicolumn{2}{|c|}{$\begin{array}{c}\text { Practice with } \\
\text { personal lists } \\
D \\
(n=200)\end{array}$}} \\
\hline & $\underset{(n=177)}{A}$ & $\underset{(n=199)}{B}$ & $\begin{array}{c}C \\
(n=200)\end{array}$ & $\begin{array}{l}\mathrm{A}+1 \\
(\mathrm{n}=\end{array}$ & & \\
\hline $\begin{array}{l}1 \text { or } 2 \\
3 \text { or } 4 \\
5 \text { or } 6 \\
7-10\end{array}$ & $\begin{array}{l}20(11) \\
63(36) \\
62(35) \\
32(18)\end{array}$ & $\begin{array}{l}20(10) \\
65(33) \\
61(31) \\
53(27)\end{array}$ & $\begin{array}{l}32(16) \\
68(34) \\
72(36) \\
28(14)\end{array}$ & $\begin{array}{r}72 \\
196 \\
195 \\
113\end{array}$ & & \\
\hline
\end{tabular}

with less personal continuity in this study perhaps because the longer measurement period increased the opportunity to consult different doctors on short term contracts, such as trainees.

Familiarity with several different doctors may be seen as a desirable consequence of less continuity in group practice. In practice $\mathbf{B}$, however, more than a quarter of patients had consulted seven or more different doctors and a tenth had consulted nine or 10 . Many of these doctors were trainees and locums; even so, $37 \%$ of patients in practice $B$ had consulted four or more of the six principals. Furthermore, in practices with combined lists and trainees $86 \%$ of children had consulted at least five doctors. Such variety seems unlikely to be due to patients' choice.

There is evidence that patients can usually consult the same doctor in a group practice if this is a high priority for the practice concerned. Marsh and KaimCaudle reported $84 \%$ of consultations with the same doctor in Stockton on Tees, ${ }^{7}$ and Roland et al found a mean of $82 \%$ in two practices with personal lists in Bristol. ${ }^{8}$ Our study shows a similar level of $83 \%$ for the practice with a personal list, and the mean of $53 \%$ for the practices with combined lists also compares well with the mean of $52 \%$ in the Bristol study. General practitioners, however, recognise many competing priorities in arranging care, including the need to minimise delay to patients requesting appointments and to share workload equally within a group. ${ }^{3}$

In our study practices $\mathrm{A}-\mathrm{C}$ each had at least two other different competing priorities, to give experience to trainees and to provide a service to more distant patients by practising from a second site. They also believed in team care without excessive dependence on individual doctors (personal communications). The observed reduction in personal continuity compared with that in practice $\mathrm{D}$ was large but not different from that in the Bristol study, in which both types of practice had trainees. Practice $\mathrm{C}$ had a policy of confining doctors to either the main or the branch surgery when possible, and this may be linked to the appreciably higher continuity recorded there. Probably a system of personal lists is necessary to achieve high levels of personal continuity for most patients of all ages in a group practice if this is wanted.

This study suggests that the concept of a named personal doctor with long term medical responsibility for patients must be questioned as it is out of step with the reality of shared care in at least some group practices today. Recent government initiatives have simplified the arrangements for patients changing doctors, and the whole thrust of both the new general practitioners' contract and the subsequent white paper' has been to encourage group practices large enough to use a range of medical and paramedical skills. One great advantage of practices with combined lists may be the opportunity for patients to exercise informed choice, and another may be the opportunity for informal audit and second opinions when partners see each other's patients. The experience of different doctors may well, however, result in conflicting advice, and the need for agreed clinical policies within groups would seem to be paramount to avoid confusing patients. Yet this came much lower in a list of general practitioners' priorities than quicker access for patients and equal workload for partners. ${ }^{4}$

In the three practices with combined lists most patients had most often consulted a doctor with whom they were not registered. Unless registration is constantly kept up to date it may be difficult to say which general practitioner is responsible for a patient's medical care. The profession has already persuaded the Department of Health to abandon a proposal to link target payments for immunisation and cervical smears to individual doctors' lists. Other priorities in modern team care such as special clinics may make consulting the same doctor less important for patients than before. General practitioners need to discuss where they stand on clinical responsibility: Should it lie with the individual doctor or with the group or team? To help answer this question more evidence is needed, particularly from patients themselves, about attitudes to personal care in general practice and of any measurable benefit when patients consult the same doctor. Meanwhile group practices may want to audit their levels of personal continuity and then consider whether to include information on this in their annual reports.

We thank the doctors and particularly the receptionists in the four practices for help with collecting data. We also thank Dr Clive Osmond for statistical advice, Mr Mark Mullee for help with handling the data, and Mrs Nita Bambury for aiding communication with the practices and handling successive drafts of the manuscript. This study was funded by the scientific foundation board of the Royal College of General Practitioners.

1 Aylett MJ. Seeing the same doctor. F R Coll Gen Pract 1976;26:47-52

2 Royal College of General Practitioners. Policy statement 1-evidence to the Royal Commission on the National Health Service. London: Royal College of General Practitioners, 1985:2.

3 Gray DJP. The key to personal care. $f R$ Coll Gen Pract 1979;29:666-78

4 Freeman GK. Priority given by doctors to continuity of care. $\mathcal{I} R$ Coll Gen Pract 1985;35:423-6.

5 Freeman GK. Receptionists, appointment systems and continuity of care. fR Coll Gen Pract 1989;39:145-7.

6 Breslau N, Reeb KG. Continuity of care in a university-based practice. $\mathcal{F}$ Med Educ 1975;50:965-9.

7 Marsh G, Kaim-Caudle P. Team care in general practice. London: Croom Helm, 1976:50.

8 Roland M, Major V, Morris R. Factors associated with achieving continuity of care in general practice. $\mathcal{R}$ Coll Gen Pract 1986;36:102-4

9 Secretaries of State for Health, Wales, Northern Ireland, and Scotland. Working for patients. London: HMSO, 1989. (Cm 555.)

(Accepted 31 August 1990) 